\title{
Effect of reservoir and production system integration on field production strategy selection
}

\author{
João C. V. Hohendorff Filho ${ }^{1, *}$ and Denis J. Schiozer ${ }^{1}$ \\ ${ }^{1}$ University of Campinas, UNICAMP, PO Box 6052, CEP 13.083-970, Campinas, São Paulo, Brazil
}

Received: 30 May 2018 / Accepted: 18 July 2018

\begin{abstract}
In petroleum engineering studies, the integration of reservoir and production system models can improve production forecasts. As the integration increases computation time, it is important to assess when this integration is necessary and how to choose a suitable coupling methodology. This work analyzes the influence of this integration, for a petroleum field in the development phase, evaluating the effects on the production strategy parameters. We tested a benchmark model based on an offshore field in Brazil so we could validate the solution in a reference known model. This work continues the research of Von Hohendorff Filho and Schiozer (2014, 2017) and aims to improve step 11 of the 12-step reservoir development and management methodology by Schiozer et al. (2015). The solution is tested in a reference model. Using the integrated production system and reservoir models from step 11 of the methodology, we re-optimize the production strategy of a standalone production development, while evaluating net present value as the objective function. We adapted an assisted workflow to include the optimization of new variables, such as pipe diameters of the well systems and gathering systems, platform positions, and artificial lift application, and compared these with the production strategy obtained from the same benchmark in a standalone approach. Comparing the integrated standalone and integrated production strategies, we observed important changes that indicate the need to integrate reservoir and production models. The optimized integrated systems resulted in significantly increased net present values, maintaining the same oil recovery factor while requiring lower initial investment. We implemented the best integrated production strategy and the integrated production strategy derived from the standalone case in the reference model which, in this case, represents a real field (emulating a real situation). Integration in the implementation step impacted the production forecast more than the optimization step, demonstrating the benefits of integrating reservoir and production systems to increase project robustness.
\end{abstract}

\section{Nomenclature and abbreviations}

CAPEX CApital EXpenditures

$d_{\mathrm{r}} \quad$ Diameter of risers

$d_{\mathrm{pl}} \quad$ Diameter of production/injection lines

$d_{\mathrm{pc}} \quad$ Diameter of the production/injection columns

FL FlowLine

KPI Key Performance Indicator

$L^{i} \quad$ Cartesian coordinates of location of well $i$

$L_{\mathrm{p}} \quad$ Cartesian coordinates of platform location

$N_{\mathrm{p}} \quad$ Cumulative oil production

NPV Net Present Value

$n_{\mathrm{w}} \quad$ Total number of wells

OPEX OPerating EXpenses

PC Production/injection Column

$q_{\mathrm{gl}}^{i} \quad$ Gas lift rate for well $i$

\footnotetext{
* Corresponding author: hohendorff@cepetro.unicamp.br
}

$q_{\mathrm{p}}^{\text {oil }}, q_{\mathrm{p}}^{\text {water }}, q_{\mathrm{p}}^{\text {liquid }}$ Limits of platform flow rate for oil, water and liquid production

$q_{\mathrm{p}}^{\mathrm{inj}} \quad$ Limit of platform flow rate for water injection

$\mathrm{R} \quad$ Riser

RF Recovery Factor

$t_{\mathrm{sd}}^{i} \quad$ Shutting down time for well $i$

$t_{\text {wo }}^{i} \quad$ Opening schedule of well $i$

$W_{\mathrm{i}} \quad$ Cumulative water injection

$w l^{i} \quad$ Length of well $i$

$W_{\mathrm{p}} \quad$ Cumulative water production

\section{Introduction}

Currently, more studies integrating reservoir and production systems in petroleum field production are needed to 
analyze the pressure interaction between reservoirs, wells, gathering networks, and surface facilities. Barroux et al. (2000), Kosmala et al. (2003), Rotondi et al. (2008), and Cotrim et al. (2011) demonstrated the necessity of integrated methodologies to couple simulators to improve production forecast reliability and quality. For instance, when the reservoir simulator fails to model the operational conditions of complex production systems, integration with the process simulator becomes even more consequential.

Integration of reservoir and production systems is a recommended best practice especially for projects involving large capital investments because of more stringent project assurance (technical and economical) and is also required by the latest subsea processing technologies. The effort to integrate these models to optimize overall system performance presents many technological challenges (Rahmawati et al., 2012). Hiebert et al. (2011) commented that during the planning and selection phase of a project, the concepts and design ideas are examined in order to mitigate risks, but these are usually constrained by the availability of expert resources and time.

More rigorous modeling is necessary because of dynamic changes in boundary conditions at coupling points between reservoir, well, and gathering systems (such as well bottom-hole, well-heads, and manifolds). Rigorous modeling also requires more appropriate methods to integrate the reservoir and production system. However, the advantages of a robust integration in the production development phase may not outweigh the increased complexity and time consumption due to the influence of reservoir uncertainties, which could be dominant parameters in the project.

Risk assessment in appraisal and development phases can be complex due to the interdependence among uncertainties, oil recovery and production strategy, and the excessive time consumption in the modeling process. In these phases, numerical reservoir simulators are generally required but some simplifications can be applied. The unintegrated approach using standalone reservoir simulations, with well capacity constraints fixed in bottom-hole to represent the production system behavior, have been adopted to speed up petroleum field development and management studies evolving uncertainties (Schiozer et al., 2015).

Guerillot and Roggero (1998) proposed a method for quantification of production uncertainties to be integrated directly in the data assimilation in a single procedure. The method enables a reservoir engineer to test production forecast scenarios and thus to better validate the model in relation to the initial reservoir knowledge. It is therefore possible to check if a production scenario is compatible with geologic data, or to quantify the production uncertainties resulting from geologic uncertainties.

Hegstad and Saetrom (2014) proposed a workflow which can generate and manage multiple realizations makes it straight forward to get robust and realistic estimates of uncertainties in in-place volumes and produced volumes. It is also used for risk mitigation and decision support as e.g. to evaluated robustness of well placement, well number, top side capacities etc.
Barroso Viseras et al (2014) proposed a methodology to obtain an in-depth understanding of the field, combined with assisted history matching techniques, leading to models that honor the long production history, enabling the development scenario to be optimized. Gaspar et al. (2016) noted several methodologies for production strategy optimization. These methodologies maximize Net Present Value (NPV) and Recovery Factor (RF) by evaluating different production strategy alternatives to exploit a field. We consider these methodologies a reliable option to quantify the impact of integration. Some works show workflows to optimize a more global strategy, combining varied procedures to deal with a high number of infrastructure alternatives. According to the authors, the combination of isolated optimization processes without a methodology to combine and organize them can significantly interfere with the final strategy selection.

Schiozer et al. (2015) proposed a 12-step methodology for decision analysis related to the development and management of petroleum fields. The steps include: (1) reservoir characterization, (2) model construction, (3) model calibration, (4) scenario generation, (5) reduction of scenarios, (6) production strategy for base case, (7) initial risk analysis, (8) representative models, (9) production strategy for each representative model, (10) production strategy under uncertainties, (11) potential improvements, and (12) final risk curve and decision analysis.

They established step 11 to identification of potential for change in the production strategy to improve chance of success based on the value of information, value of flexibility and robustness of the production strategy, implying in possible modifications and final strategy. They suggested the integration of reservoir simulation with production systems in step 11 to identify potential for change in the production strategy and so increase the NPV, RF, and/or other parameters. They also suggested the need for integration in step 11 after selecting the production strategy considering simplified boundary conditions for wells in previous steps as dynamic changes in boundary conditions can positively or negatively affect the NPV. For steps $6-10$, the reservoir simulation model must be complete but fast enough to generate a reliable result of each scenario.

This work verifies the impact of this suggestion comparing optimized production strategies for a typical offshore field in Brazil, evaluating whether integration affects development decisions in the production phase, as presented in Von Hohendorff Filho and Schiozer (2017). We compared these two approaches: (1) optimization without integration (standalone), setting boundary conditions at well bottomhole; and (2) optimization with integration (integrated), allowing interaction between reservoir, well, and gathering systems at the coupling point. We based the optimization process for the integrated production strategy on the methodology by Gaspar et al. (2016).

The best production strategy obtained is then implemented in a reference model (used as the real field). Observed changes in production strategy indicate whether or not to integrate reservoir and production systems in the decision-making process. 


\section{Objectives}

The main objective of this work is to confirm whether the integration of reservoir, well, and production-system models achieves a more robust production strategy in the closed loop 12-step methodology.

We also compare the impact of integrated production system modeling on production forecasts, NPV, and development decisions related to the production phase by testing implementation of production strategies (optimized in a representative model) in the reference model, considered a real field.

\section{Optimization for production systems}

The complete infrastructure (production system) comprises components that can include size, location and arrangement of surface facilities, number, position and completion of wells, injection and production capacities, well opening schedules, use of intelligent wells, among others (Gaspar et al., 2016). Some of these characteristics are required by reservoir engineers, focusing on the reservoir system.

Production engineers then optimize characteristics related to well systems which include dimensions, diameters and operational conditions for wellheads, injection and production columns, and artificial lift equipment (for instance gas lift). The same components for gathering systems are also optimized, including connections, flowlines, risers, manifolds and other subsea equipment (Oliveira, 1989).

According Nwakile et al. (2011) optimization of production system can be achieved by investigating multiple design scenarios with an experimental design and optimization framework. They proposed a framework for optimization gas field facility design and their comparison between the base case model and the optimized case showed an improvement in NPV.

Tillero et al. (2014) proposed a workflow to aim assure to users the expected behavior from integrated simulation of petroleum production system considering its nature, convergence criteria previously set for the simulation process and user needs.

Pipeline network and surface facilities are designed to optimize the combination of oil recovery, CApital EXpenditures (CAPEX), and OPerating EXpenses (OPEX). This requires a reliable, integrated model to calculate injection and predict production and so assess the overall economics of the project (Campozana et al., 2008).

Development decisions specific to production systems include platform (topsides) locations, production and injection liquid handling capacity of platforms, and geometrical and operational characteristics for well and gathering systems. These components impact injection and production, influencing production strategy optimization.

Developing projects for reservoir and production system is a complex task, because both systems interact directly during whole exploitation time. Therefore, decisions related to number of variables as number and position of wells, tubing performance capacity, CAPEX etc. are affected by both systems.
A most notable example is well location, which involves reservoir completion and length of risers, flow lines and production/injection columns. A great effort is demanded in this optimization step and several researchers (Abellan and Noetinger, 2010, Bouzarkouna et al., 2011, 2013, Fonseca and Araújo, 2016 and Yang et al., 2007) have evaluated methods to reduce the computational cost.

Platform location influences both connection investments and well completion, and directly depends on well placement, longer distances increase the pressure inside the pipes and reduce well rates. It is an optimization problem with two objectives: to maximize production and recovery, and to minimize investments. In this way, NPV is a Key Performance Indicator (KPI) for this evaluation.

The location is restricted by subsea topography, environmental constraints, existing pipelines and recommended safety distances for subsea systems and Christmas trees, requiring a constrained optimization study.

Campozana et al. (2008) evaluated various alternatives of platform location and pipeline diameters using a global optimization tool, simultaneously solving surface network and subsurface models. Their results increased NPV over the base case, which was the initial platform location suggested by the subsea team.

Rosa and Martins Ferreira Filho (2012) proposed a general method to optimize platform and manifold locations in offshore projects by maximizing the NPV of the project. The authors commented that finding the best offshore facilities location means minimizing the total length of pipelines. Because the distance between wells and platforms is directly related to productivity, increased distance means reduced production.

Gaspar et al. (2016) noted that platform capacity impacts the operational constraints and economic KPI of the field, directly influencing revenue and indirectly influencing operating costs and taxes. The production adopted and liquid injection handling capacity directly affects the drainage rate of a petroleum field. Selecting the capacity has two objectives: to maximize production and minimize investments and costs, NPV is used as the KPI for this evaluation.

Magalhães et al. (2005), and Bento and Schiozer (2010) indicated that platform restrictions influence the final strategy, both in the number of wells given the limited number of slots available and their position in the reservoir reaching peripheral locations.

Oliveira (1989) commented that well and gathering systems have geometric and operational characteristics derived from (1) the combination of pipe elements such as production or injection columns, flowlines, risers, manifolds, and chokes; (2) their own characteristics as linear length, tilt angle and diameter; and (3) their interconnections. All pipe elements require multiphase flow correlations that apply to each pipe segment, the fluid behavior correlations for each well, the relative roughness of the pipe, and the temperature gradient along the pipes.

The behavior of components related to methods of artificial lift for reservoir fluids must also be described. These components are incorporated into the production system as separators, pumps, gas lift valves and other equipment, which affect pressure and well inflow. 
Ray and Sarker (2007) used an evolutionary algorithm to solve a practical gas lift optimization problem for oil production. We introduce a multi-objective formulation, eliminating daily problem solving while maintaining the quality of solutions.

Mahmudi and Sadeghi (2013) developed an integrated mathematical model to track the spatial and temporal variations of components in gas lift systems. The model was coupled to a combination of a genetic algorithm and the Marquardt optimization method to determine the process parameters that optimize the long-term economic return of an oil field.

All these characteristics affect well productivity, directly and indirectly influencing revenue, operating costs and taxes, resulting in an optimization problem with two objectives: to maximize production and minimize investment and costs.

Victorino et al. (2016) quantified the influence of geometrical characteristics of well and gathering systems in pressure drops for producer wells, oil recovery, and NPV for a Brazilian case scenario.

\section{Methodology}

To evaluate the impact of integrated reservoir and production systems, we first assessed development decision changes for the production phase comparing design parameters, control parameters, and performance results from an optimized production strategy for a representative model. This concept is common in decision-making processes based on models as it avoids poor choices leading to incorrect conclusions.

We compare these variables for optimized strategies both standalone and integrated: (1) design parameters such as the number, length and position of wells, opening schedule for wells, platform flow-rate limits, platform location, and geometrical characteristics of well and gathering systems; (2) control parameters such as the shutting time for wells and gas-lift rates; and (3) performance results such as (NPV), cumulative oil production (Np), cumulative water production $(\mathrm{Wp})$, and cumulative water injection (Wi). We cross validate the optimization results to confirm impact.

We also compare results for a reference model as the real field for (1) the integrated production strategy obtained in a previous step and (2) the integrated production strategy derived from standalone base strategy.

\subsection{Optimization step}

The optimization problem, described by Gaspar et al. (2016), was modified to include new design and control variables for production systems. The infrastructure design comprises the number, length and position of wells, well opening schedule, and platform flow-rate limits. We also included the platform location and geometrical characteristics of wells and gathering systems.

The design variables vector that represents the infrastructure project includes limits of platform flow rates $\left(q_{\mathrm{p}}^{\text {oil }}, q_{\mathrm{p}}^{\text {water }}, q_{\mathrm{p}}^{\text {liquid }}, q_{\mathrm{p}_{j}}^{\text {inj }}\right)$ well number $\left(n_{\mathrm{w}}\right)$ position of wells $\left(L^{i}\right)$, well length $\left(w l^{i}\right)$, opening schedule of wells $\left(t_{\mathrm{two}}^{i}\right)$, and new variables such as platform location $\left(L_{\mathrm{p}}\right)$, diameter of risers $\left(d_{\mathrm{r}}\right)$, diameter of production/injection lines $\left(d_{\mathrm{pl}}\right)$ and diameter of the production/injection columns $\left(d_{\mathrm{pc}}\right)$.

$$
\begin{aligned}
\hat{v}^{T}= & \left\{q_{\mathrm{p}}^{\text {oil }}, q_{\mathrm{p}}^{\text {water }}, q_{\mathrm{p}}^{\text {liquid }}, q_{\mathrm{p}}^{\text {inj }}, n_{\mathrm{w}}, L^{1}, \ldots L^{n_{\mathrm{w}}}, w l^{2}, \ldots w l^{n_{\mathrm{w}}},\right. \\
& \left.t_{\mathrm{wo}}^{1}, \ldots, t_{\mathrm{wo}}^{n_{\mathrm{w}}}, n_{\mathrm{p}}\right\}
\end{aligned}
$$

The control variables represent the future control alternatives for equipment, which are required to evaluate the design variables. The control variables vector that represents the operational management includes shut-in time for wells $\left(t_{\mathrm{sd}}^{i}\right)$ and the new variable gas lift rate $\left(q_{\mathrm{gl}}^{i}\right)$.

$$
\hat{w}^{T}=\left\{t_{\mathrm{sd}}^{1}, \ldots, t_{\mathrm{sd}}^{n_{\mathrm{w}}}, q_{\mathrm{gl}}^{1}, \ldots, q_{\mathrm{gl}}^{n_{\mathrm{w}}}\right\}
$$

To calculate the objective function, NPV, the equations and parameters remain similar to those of Gaspar et al. (2015). The objective function considers net cash flow over a field lifetime. In this project, the net cash flow for each period may be calculated based on the Brazilian R\&T fiscal regime considering gross revenues from oil and gas sales, total amount paid in royalties charged over gross revenue, total amount paid in special taxes on gross revenue, operational production costs associated to the oil and water production and water injection, corporate tax rate, investments on equipment and facilities and abandonment cost.

We modified the assisted optimization workflow by Gaspar et al. (2016) to include additional steps for production system integration. We define initial guesses for diameters of Risers (R), FlowLines (FL), and Production/ injection Columns (PC), gas lift rate, and platform position, and define optimization steps of these variables in isolated processes, as shown in Figure 1.

The assisted optimization begins with an initial estimate of the number and location of wells, limits of platform flow rates, and the well opening schedule. The optimization process follows a particular order based on the importance of each expected design variable. But as some specific questions about well and gathering systems optimization remain, we define other start points and conditions for the assisted optimization, as initial guess of diameters and operational constraint assumptions.

To initially estimate diameters of risers and production/ injection lines of gathering system, and production/injection columns of the well system, we used the methodology presented by Victorino et al. (2016). And we also used the configuration that generated similar results for overall production and NPV as the base strategy.

\subsection{Cross validation step}

We select specific values to cross validate the methodology results: (1) base strategy, simulated without integration; (2) base strategy, simulated with integration; (3) best strategy for integrated modeling, simulated with integration; and (4) best strategy for integrated modeling, 


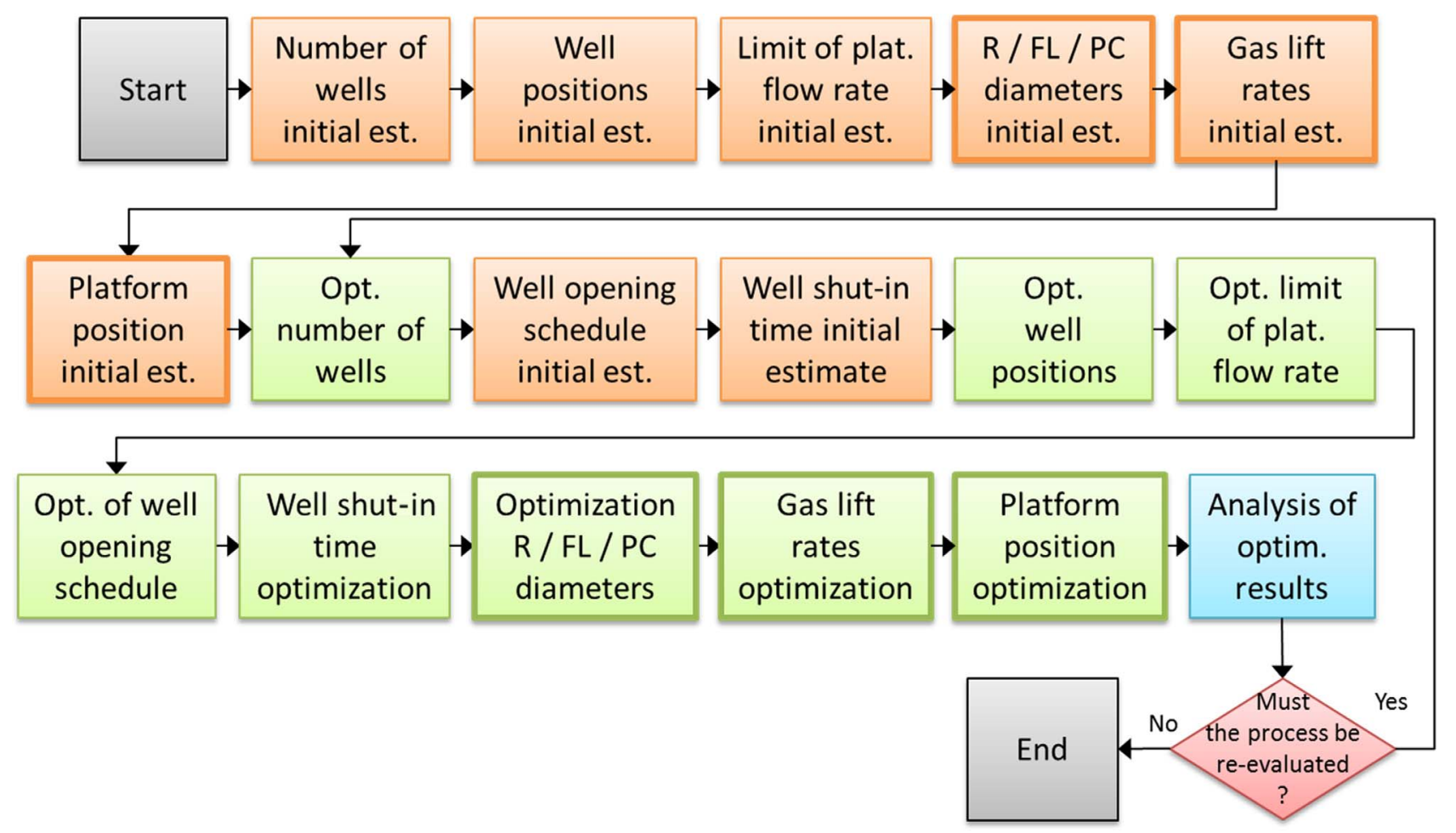

Fig. 1. Optimization workflow for the defined problem (adapted from Gaspar et al., 2014).

simulated without integration. For NPV, the four most notable values are:

- NPV-D - NPV for base strategy, simulated without integration;

- NPV-DI - NPV for base strategy, simulated with integration (first point after NPV-D);

- NPV-I - NPV for best strategy for integrated modeling, simulated with integration (maximum point);

- NPV-ID - NPV for best strategy for integrated modeling, simulated without integration.

We cross validate the NPV for best strategy for integrated modeling, simulated without integration, which must be always lower than that of the base strategy without integration, if the base strategy is assumed as a global optimum for standalone optimization. The opposite indicates that base strategy is at a local optimum for standalone optimization and the methodology is insufficient to result in realistic NPV increases. The NPV for the base strategy for standalone optimization, simulated with integration, must be lower than best strategy for integrated modeling, simulated with integration, indicating the efficiency of the optimization.

\subsection{Implementation step}

We apply production strategies in a reference model, used as the real field, to assess benefits and robustness from integration in production strategy selection.

We compare performance results (NPV, Np, Wp, and $\mathrm{Wi}$ ) for the best integrated case with integrated production strategy derived from the standalone base strategy. The standalone base strategy will be integrated using the best option for production system parameters (platform position, diameters, and gas lift rate) from the optimization step.

To apply each production strategy, the coordinates $X$, $Y$, and $Z$ of each well are transferred from the representative model to the reference model considering minor adjustments allowed by drilling well log information.

To confirm the robustness of the best optimized production strategy, we include a risk analysis with all representative models that represent probable scenarios.

\section{Application}

The optimization methodology is applied to the UNISIMI-D benchmark case (Gaspar et al., 2015) to determine the design and operational variables necessary to find the optimum development strategy. The reservoir is represented by a corner point grid with 37000 active cells.

UNISIM-I-D represents a field in the initial stages of field management planning under uncertainties. After selecting some Representative Models (RM) to assess the quality of decisions considering uncertainties, the production strategy of each RM is defined.

This work used the optimized production strategy E9, of benchmark UNISIM-I-D, the best strategy in Schiozer et al. (2015) following 10 steps considering several types of uncertainties. We considered E9 as the best strategy without integration for standalone subsurface model with well bottom-hole pressure and rate constraints. The design 

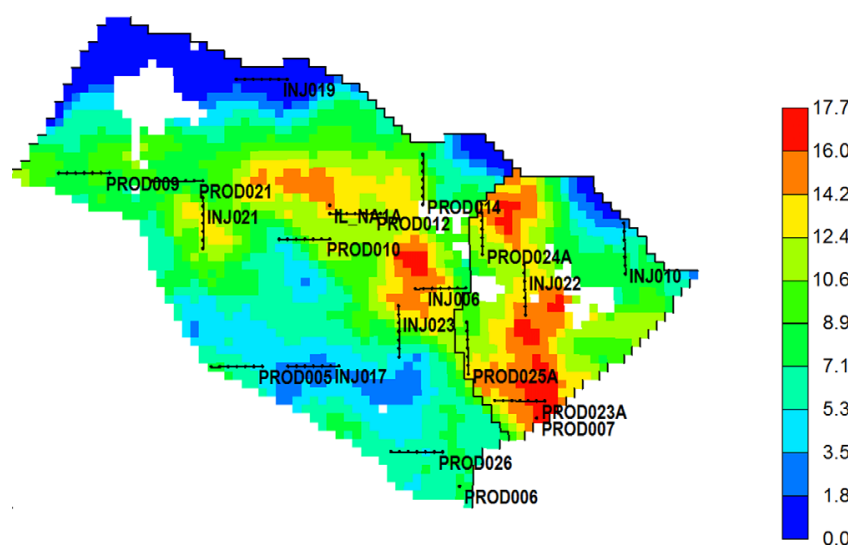

Fig. 2. Well and platform locations for optimized standalone model.

parameters considered in optimization were: number, type (vertical or horizontal), location and schedule of wells and capacities constraints (liquid, oil and water production and water injection) of platform. The control variables were: maximum water-cut, maximum liquid production and water injection of wells.

In Gaspar et al. (2015) and Schiozer et al. (2015), fluid rates and bottom-hole pressures were applied as well boundary conditions to maintain the average field pressure above the bubble point pressure. Neither considered integration with the production system, simulating a subsurface standalone model.

The production system of RM9 was used to determine the new design and operational variables (Schiozer et al., 2015). This RM represents the best scenario for the field. Other RMs (MR1 to MR8) were used to check the robustness of optimized production strategies in the implementation step.

E9 was used for the initial production strategy in Step 11 to integrate reservoir and production system (as shown in Fig. 2). We used conventional black oil simulator IMEX $^{\mathrm{TM}} 2014$ for reservoir simulations.

We used the empirical correlations of tubing multiphase flow by Brill and Beggs (1991) to model all satellite producer wells (Victorino et al., 2016), and the Standing correlations (Standing, 1947) to model fluids. These correlations were included in the multiphase flow simulator Ptube ${ }^{\text {TM }} 2014$ $(C M G)$. Figure 3 shows the satellite well pattern adopted for producer wells. Well position and platform location were used to define riser, flowline and production/injection column lengths, and gas lift valve distance from the bottom, and also define well completions in the reservoir.

We defined three integrated optimization cases that are related to well boundary condition changes in the subsurface standalone base strategy (Optimizations A, B, and C).

Optimization $\mathrm{A}$ is the basic procedure to integrate reservoir and production systems. As bottom-hole pressures and rates for wells can be estimated directly from the integration with well and gathering systems, we disregarded all operational constraints for producer wells from the base strategy.
We also removed base strategy operational controls for maximum liquid flow rates and minimal bottom-hole pressures for the producer wells, defined by the multiphase flow simulator with wellhead pressure restricted to $15 \mathrm{kgf} / \mathrm{cm}^{2}$.

Optimization B is similar to A, but only the bottomhole pressure constraint from the base strategy is replaced with wellhead pressure. All other constraints of the base strategy are maintained to verify the influence of rate limits on integration for producer wells.

We removed operational control for minimal bottomhole pressure for the producer wells, as these are dynamically defined by the multiphase flow simulator operating with the minimum wellhead pressure of $15 \mathrm{kgf} / \mathrm{cm}^{2}$. Original design variables and control variables from the standalone original base strategy remain unaltered, except the initial estimate of control variables involving well shut-in time for wells that remains open until the end of the productive life of the field $\left(t_{\mathrm{sd}}^{i}=0.95\right)$.

For platform, $q_{\mathrm{p}}^{\text {oil }}, q_{\mathrm{p}}^{\text {water }}, q_{\mathrm{p}}^{\text {liquid }}, q_{\mathrm{p}}^{\text {inj }}$ and $n_{\mathrm{w}}$ values are shown in Table 1 . For wells, $L^{1}, w \dot{l}$, and $t_{\text {wo }}^{i}$ values are shown in Table 2.

We used the direct search method (Maschio et al., 2008) to optimize number and position of wells, opening schedule for wells, and platform flow-rate limits in determined steps around the starting point.

We used the estimates from Victorino et al. (2016) for pipe diameters and control variables including gas lift rates. Table 3 summarizes diameters for risers ( $\mathrm{R}$ ) and flowlines (FL) used for the gathering system configuration, and production/injection columns (PC) and gas lift rate (Qgi) used for the well system configuration.

Victorino et al. (2016) determined the suitable inner diameters for integrated Optimizations $\mathrm{A}$ and $\mathrm{B}$, with $d_{\mathrm{r}}=6^{\prime \prime}, d_{\mathrm{pl}}=6^{\prime \prime}, d_{\mathrm{pc}}=4^{\prime \prime}$, without an artificial gas lift $\operatorname{method}\left(q_{\mathrm{gl}}^{i}=0\right.$ for all wells). In this work, gas lift rates are the same for all wells.

Optimization C has similar constraints as Optimization $\mathrm{B}$ but different initial estimates for the well and gathering systems. We tested several well and production gathering systems parameters and selected the configuration that generated results (overall production and NPV) closest to the base strategy.

For Optimization $\mathrm{C}$, we selected inner diameters for the integrated case $d_{\mathrm{r}}=8^{\prime \prime}, \quad d_{\mathrm{pl}}=6^{\prime \prime}, \quad d_{\mathrm{pc}}=4^{\prime \prime}, \quad$ with $q_{\mathrm{gl}}^{i}=200000 \mathrm{~m}^{3} /$ day for all wells, resulting in field production and injection rates similar to the base strategy.

With few combinations of pipe diameters, all promising combinations are evaluated in the optimization process. To analyze gas lift rates, we tested all plausible alternatives defined at the beginning of the process for each combination of pipe diameters.

We calculated the overall cost of well connection, for all wells, to the platform to determine the initial estimate for platform locations $\left(L_{\mathrm{p}}: X=355,400 ; Y=7516,700\right)$. We applied the direct search method (Maschio et al., 2008) to optimize platform location in determined steps around the starting point.

The explicit methodology by Von Hohendorff Filho and Schiozer (2014) is the base for our work to integrate reservoir, well, and gathering systems. Our methodology is 


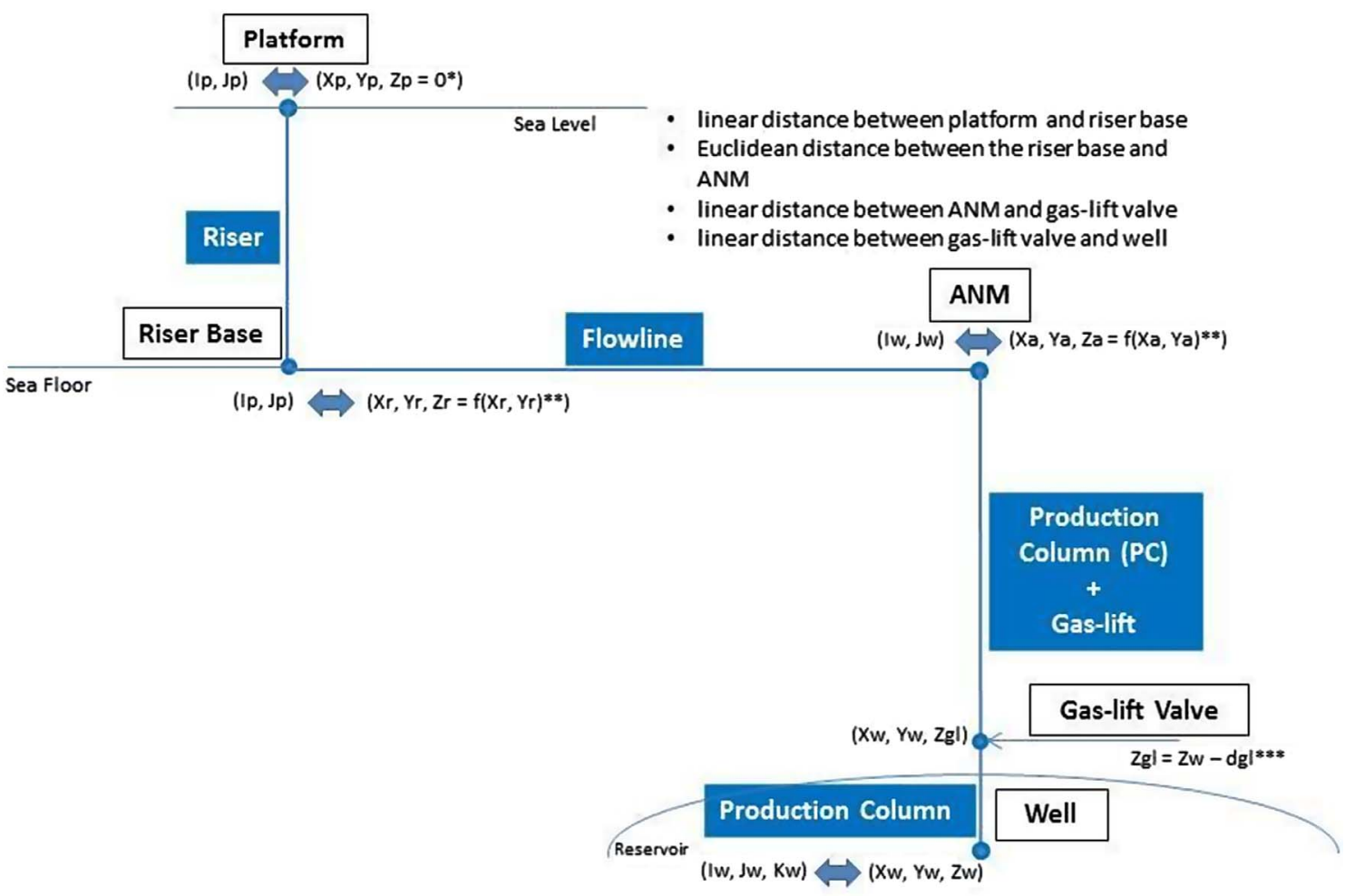

Fig. 3. Satellite well template for producers.

Table 1. Design variables for platform.

\begin{tabular}{ccc}
\hline Variable & Value & Unit \\
\hline$q_{\mathrm{p}}^{\text {oil }}=q_{\mathrm{p}}^{\text {liquid }}$ & 20150 & $\mathrm{~m}^{3} /$ day \\
$q_{\mathrm{p}}^{\text {water }}$ & 9765 & $\mathrm{~m}^{3} /$ day \\
$q_{\mathrm{p}}^{\text {inj }}$ & 28210 & $\mathrm{~m}^{3} /$ day \\
$n_{\mathrm{w}}$ & 20 & - \\
\hline
\end{tabular}

enhanced by generating lift curves for each producer during the integrated simulation, avoiding unnecessary multiphase flow simulations. We achieved times for explicit runs using our methodology similar to decoupled runs with pre-generated lift curves for producer wells.

Table 4 summarizes parameters applied to objective functions for economic evaluation (Gaspar et al., 2015). Table 5 summarizes additional economic parameters for production systems.

To evaluate the impact of integration in production strategy selection, a reference model, used as the real field, is needed to implement integrated production strategies. Avansi and Schiozer (2015) created the UNISIM-I benchmark to test methodologies in synthetic models with real reservoir characteristics. Based on the Namorado Field (Campos Basin) in Brazil, the case includes a reference model, UNISIM-I-R.

UNISIM-I-R is a geologic model representing a sandstone reservoir of turbiditic origin and is constructed based on structural, facies and petrophysical models, using real information from 56 wells drilled in the Namorado Field. The reservoir is represented by a corner point grid with 3.4 million active cells.

During the implementation of each production strategy, the coordinates $X, Y$, and $Z$ of each well are transferred from the RM to the reference model considering minor adjustments in $Z$ to complete wells in closer high permeability layers.

For risk analysis, production system variables of the integrated base strategy from the RMs were defined using the initial estimates of design variables including pipe diameters and control variables related to gas lift rates for the best production strategy after optimization.

\section{Results}

\subsection{Optimization step}

Figures 4-6 show the evolution of NPV during the global optimization process for the three optimizations A, B, and C of RM9. All optimizations demanded dozens of run simulations and focused more in specific production system details, as platform position, pipe diameters and gas lift rate. There is clear the impact of these variables for all optimizations.

Figures 7-9 show variations in NPV and oil recovery factors for each global optimization step. The results show similar results and trends for all optimizations.

For the overall process, optimizing well placement and different components of the well and gathering systems 
Table 2. Design variables and control variables for wells.

\begin{tabular}{|c|c|c|c|c|c|c|c|c|c|}
\hline \multirow{2}{*}{$\begin{array}{c}\text { Well } \\
\text { PROD005 }\end{array}$} & \multicolumn{2}{|c|}{$L^{i}(I, J)$} & \multirow{2}{*}{$\frac{w l^{i}(\mathrm{~m})}{600}$} & \multirow{2}{*}{$\frac{\begin{array}{c}t_{\mathrm{wo}}^{i} \\
\text { (days) }\end{array}}{2099}$} & \multirow{2}{*}{$\begin{array}{c}\text { Well } \\
\text { PROD025A }\end{array}$} & \multicolumn{2}{|c|}{$L^{i}(I, J)$} & \multirow{2}{*}{$\frac{w l^{i}(\mathrm{~m})}{600}$} & \multirow{2}{*}{$\frac{t_{\mathrm{wo}}^{i}(\text { days })}{2313}$} \\
\hline & 24 & 17 & & & & 54 & 22 & & \\
\hline PROD006 & 53 & 3 & Vertical & 2436 & PROD026 & 45 & 7 & 600 & 2344 \\
\hline PROD007 & 62 & 11 & Vertical & 2160 & INJ006 & 54 & 26 & 600 & 2191 \\
\hline PROD009 & 6 & 40 & 600 & 2040 & INJ010 & 73 & 34 & 600 & 2009 \\
\hline PROD010 & 32 & 32 & 600 & 1948 & INJ017 & 33 & 17 & 600 & 2283 \\
\hline PROD012 & 38 & 35 & 600 & 1979 & INJ019 & 27 & 51 & 600 & 1918 \\
\hline PROD014 & 49 & 42 & 600 & 2221 & INJ021 & 23 & 31 & 600 & 2071 \\
\hline PROD021 & 17 & 39 & 600 & 2405 & INJ022 & 61 & 23 & 600 & 2130 \\
\hline PROD023A & 57 & 13 & 600 & 1857 & INJ023 & 46 & 18 & 600 & 2374 \\
\hline PROD024A & 56 & 36 & 600 & 1887 & IL NA1A & 38 & 36 & Vertical & 2252 \\
\hline
\end{tabular}

Table 3. Values of design and operational parameters.

\begin{tabular}{ccc}
\hline $\mathrm{ID}[\mathrm{PC}](\mathrm{in})$ & $\mathrm{ID}[\mathrm{FL} / \mathrm{R}](\mathrm{in})$ & $q_{\mathrm{gl}}^{i}\left(\mathrm{~m}^{3} /\right.$ day $)$ \\
\hline 3.0 & 4.0 & 0 \\
4.0 & 6.0 & 100,000 \\
5.0 & 8.0 & 200,000 \\
\hline
\end{tabular}

required more simulations but also increased NPV the most, while subsequent steps requiring fewer simulations increased the objective functions less. Optimization significantly increased NPV.

When optimizing pipe diameters and artificial lift rates, we tested both parameters with all combinations of riser, flowline, and production/injection diameters above the initial guess and all combinations of artificial lift rates. Results showed the combination of diameters to be a high-impact decision variable when optimizing production strategies.

The optimized pipe diameter combinations for A, B and, C were $\quad d_{\mathrm{r}}=8^{\prime \prime}, \quad d_{\mathrm{pl}}=8^{\prime \prime}, \quad d_{\mathrm{pc}}=5^{\prime \prime}, \quad$ with $\quad q_{\mathrm{gl}}^{i}=$ $200,000 \mathrm{~m}^{3}$ /day for all wells. The importance of considering the artificial lift method is observed in the Diameter \& Gas Lift optimization step and highlighted by Victorino et al. (2016).

To analyze the impact of overall flow rates of liquid production and water injection, we modified the limits of platform flow rates to improve NPV.

The results showed small changes in platform capacities, with $q_{\mathrm{p}}^{\text {oil }}$ and $q_{\mathrm{p}}^{\text {liquid }}$ changing from 9765 to $10,462.5 \mathrm{~m}^{3}$ /day for all cases (7\%), and $q_{\mathrm{p}}^{\text {inj }}$ changed from 28,210 to 29,285 $\mathrm{m}^{3}$ /day for Optimizations B and C $(3 \%)$. The Platform optimization step (Figs. 7-9) shows an even stronger impact on oil recovery.

Figures 10-12 show well and platform locations after global optimization for the optimizations A, B, and C. Optimizing $L_{p}$ resulted in a $200 \mathrm{~m}$ shift from its original estimated position for Optimizations $\mathrm{A}$ and $\mathrm{B}$, considering restrictions for the platform positioning as the minimal distance for well-heads. The changes in NPV and RF are insignificant for the Platform Position optimization step.
To optimize the number of wells, we analyzed the economic performance indicators $\mathrm{NPV}_{\mathrm{p}}$ and $\mathrm{NPV}_{\mathrm{i}}$ for each individual well with equations presented in Gaspar et al. (2015) and eliminated wells with negative economic performance, i.e., the well exclusions contribute positively to NPV. In this step, we removed the vertical injector well INJ017 in all cases improving the NPV but reducing RF, as shown in the Well Number Refinement optimization step.

To optimize Well Opening Schedules, we tested only two potential wells in the schedule with new opening dates to increase NPV because of the INJ017 removal. The opening date for injector well INJ023 was brought forward to 2283 days in Optimizations B and C and; producer well PROD-06, 2283 days in Optimization A, with little impact in NPV and FR, as seen in the Well Opening Schedule optimization step.

In the Well Placement re-optimization step, we moved the wells to neighboring grid blocks in one aleatory step for each well. In each case, four wells were moved to regions near their original locations: Optimization A - INJ023, PROD021, PROD006; Optimization B - PROD010, PROD021, INJ021, PROD007; and Optimization C - INJ023, PROD012, INJ021, PROD023A. PROD014 was rotated $90^{\circ}$ in all cases. Results show that well placement remains a high-impact decision variable when optimizing the production strategy.

In the shut-in producers optimization step, we tested to decrease the initial water cut for each well to $90 \%$ to evaluate time to shut-in wells. NPV did not improve with the optimized shut-in time for producer wells, indicating that this variable had already achieved optimum values.

Table 6 gives the results of NPV, $N_{\mathrm{p}}, W_{\mathrm{p}}$ and, $W_{\mathrm{i}}$ (for Optimizations A, B and C) to show the effect of the integration relative to integrated base production strategy and how integrating the production system affects the economic return and production forecast. The results for integration showed similar values for NPV and $N_{\mathrm{p}}$ for Optimizations $\mathrm{A}$ and $\mathrm{B}$. The production strategy selected for Optimization $\mathrm{C}$ considered the forecast from the base strategy with similar results. 
Table 4. Economic scenario.

\begin{tabular}{lcc}
\hline \multicolumn{1}{c}{ Variable/Parameter } & Value & Unit \\
\hline Oil price & 314.5 & $\mathrm{USD} / \mathrm{m}^{3}$ \\
Oil production cost & 62.9 & $\mathrm{USD} / \mathrm{m}^{3}$ \\
Water production cost & 6.29 & $\mathrm{USD} / \mathrm{m}^{3}$ \\
Water injection cost & 6.29 & $\mathrm{USD} / \mathrm{m}^{3}$ \\
Investment in drilling and completion of horizontal well & 61.17 & $10^{3} \mathrm{USD} / \mathrm{m}$ \\
Investment in connection (well-platform) of horizontal well & 13.33 & $\mathrm{USD} \mathrm{millions}$ \\
Investment in drilling and completion of vertical well & 21.67 & $10^{3} \mathrm{USD} / \mathrm{m}$ \\
Investment in connection (well-platform) of vertical well & 13.33 & $\mathrm{USD}$ millions \\
Investment in platform & Equation $(1)$ & $\mathrm{USD}$ millions \\
Abandonment cost (\% investment on drilling and completion) & 8.20 & - \\
Annual discount rate (\%) & 9.00 & - \\
Corporate tax rate (\%) & 34.00 & - \\
Social taxes rates - charged over gross revenue (\%) & 9.25 & - \\
Royalties rate - charged over gross revenue (\%) & 10.00 & - \\
\hline
\end{tabular}

Table 5. Additional economic parameters for production system.

\begin{tabular}{|c|c|c|c|c|}
\hline Economic parameter & $\begin{array}{l}\text { Technical parameter/decision } \\
\text { variable }\end{array}$ & $\begin{array}{l}\text { Value } \\
\text { ID }\end{array}$ & Cost & Unit \\
\hline \multirow{7}{*}{$\begin{array}{l}\text { Investment in connection (well-platform) of vertical/ } \\
\text { horizontal well }\end{array}$} & \multirow[t]{3}{*}{ Production/injection flowline } & $4^{\prime \prime}$ & 411 & \multirow[t]{3}{*}{$\mathrm{USD} / \mathrm{m}$} \\
\hline & & $6^{\prime \prime}$ & 768 & \\
\hline & & $8^{\prime \prime}$ & 1976 & \\
\hline & \multirow[t]{3}{*}{ Riser } & $4^{\prime \prime}$ & 879 & \multirow[t]{3}{*}{$\mathrm{USD} / \mathrm{m}$} \\
\hline & & $6^{\prime \prime}$ & 1513 & \\
\hline & & $8^{\prime \prime}$ & 2597 & \\
\hline & Riser and flowline installation & - & 11.70 & $\begin{array}{l}\text { USD } \\
\text { millions }\end{array}$ \\
\hline \multirow[t]{4}{*}{ Investment in drilling and completion of vertical well } & \multirow[t]{3}{*}{ Production column } & $3^{\prime \prime}$ & 234 & \multirow[t]{3}{*}{$\mathrm{USD} / \mathrm{m}$} \\
\hline & & $4^{\prime \prime}$ & 250 & \\
\hline & & $5^{\prime \prime}$ & 270 & \\
\hline & Drilling and completion & - & 20.90 & $\begin{array}{l}\text { USD } \\
\text { millions }\end{array}$ \\
\hline \multirow[t]{5}{*}{ Investment in drilling and completion of horizontal well } & \multirow[t]{3}{*}{ Production column } & $3^{\prime \prime}$ & 234 & \multirow[t]{3}{*}{$\mathrm{USD} / \mathrm{m}$} \\
\hline & & $4^{\prime \prime}$ & 250 & \\
\hline & & $5^{\prime \prime}$ & 270 & \\
\hline & \multirow[t]{2}{*}{ Drilling and completion } & - & 21185 & $\begin{array}{c}\mathrm{USD} / \mathrm{m} \\
\text { horiz }\end{array}$ \\
\hline & & - & 25.66 & $\begin{array}{l}\text { USD } \\
\text { millions }\end{array}$ \\
\hline \multirow[t]{4}{*}{ Investment inrecompletion of vertical well } & \multirow[t]{3}{*}{ Production column } & $3^{\prime \prime}$ & 29 & \multirow[t]{3}{*}{$\mathrm{USD} / \mathrm{m}$} \\
\hline & & $4^{\prime \prime}$ & 45 & \\
\hline & & $5^{\prime \prime}$ & 65 & \\
\hline & Workover & - & 7.86 & $\begin{array}{l}\text { USD } \\
\text { millions }\end{array}$ \\
\hline \multirow[t]{2}{*}{ Additional investment in connection for Artificial-Lift } & Injection flowline $4^{\prime \prime}$ & - & 411 & $\mathrm{USD} / \mathrm{m}$ \\
\hline & Riser $4^{\prime \prime}$ & - & 879 & $\mathrm{USD} / \mathrm{m}$ \\
\hline
\end{tabular}




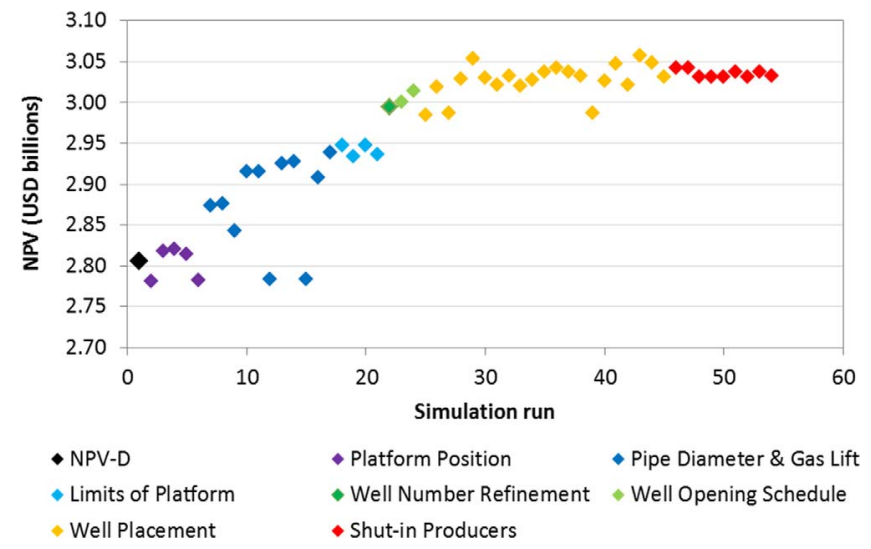

Fig. 4. NPV evolution for Optimization A during the global optimization process.

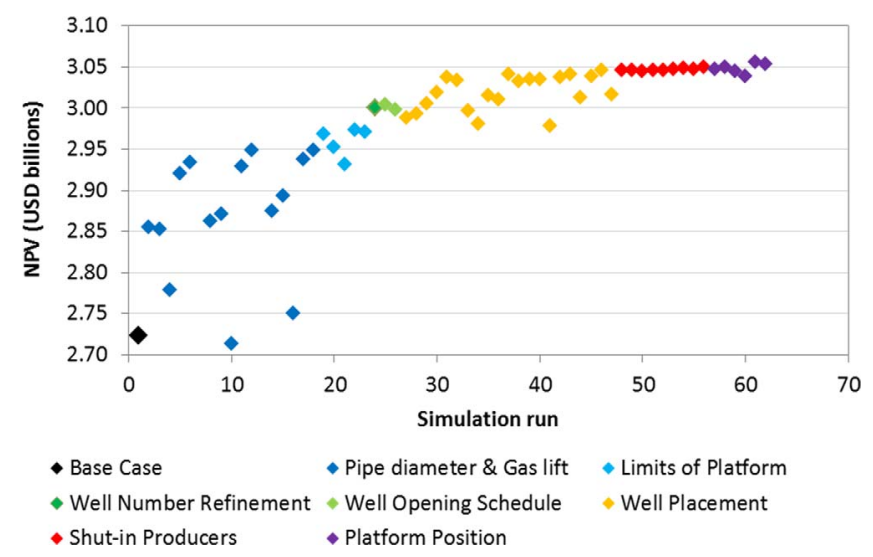

Fig. 5. NPV evolution for Optimization B during the global optimization process.

\subsection{Cross validation step}

Comparing NPV-D for base strategy E9 (2.88 USD billion) with NPV-DI for all optimizations, we can see effects of the integration in the original standalone production strategy (E9). For Optimizations A (2.81 USD billion) and B (2.72 USD billion), NPV is lower than the base strategy (E9). Only the results for Optimization C are similar (2.87 USD billion), which we selected as the ideal estimate for well system and gathering system parameters.

Table 7 compares the results of the best strategies for integrated Optimizations A, B, and C with the re-optimized integrated base production strategy (NPV-DI to NPV-I). Increased gains in both NPV and Np are the clear benefits of optimizing all markers. The integration dynamically altered boundary conditions at coupling points, which affected all well results and redefined the production strategy.

NPV-I shows the benefits (increased NPV) of optimization in the integrated base strategy (NPV-DI) because NPV-DI was initially optimized without considering integration effects (dynamic boundary conditions at coupling points were not considered) affecting all well results. All

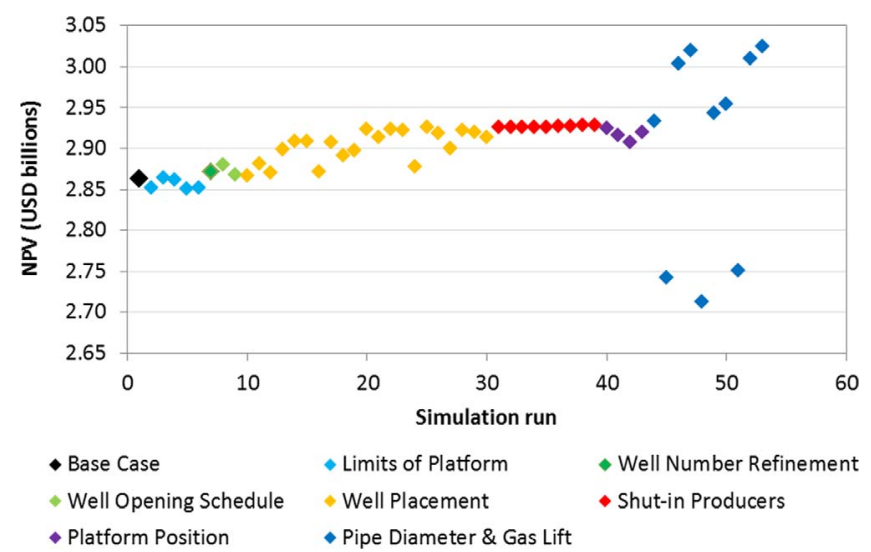

Fig. 6. NPV evolution for Optimization $\mathrm{C}$ during the global optimization process.

optimizations present improved NPV-D values, indicating that NPV-DI was sub-optimized for fluid rates and wellhead pressures as well boundary conditions.

Comparing results from Optimizations B and C, we can see differences in the values of NPV, Np, Wp, and Wi between the initial estimates suggesting, in this example, that when to optimize production system parameters in a global optimization process is highly influential.

As we excluded operating restrictions for a maximum liquid rate per well in Optimization A (a natural step since the rates are a consequence of the integration), the $\mathrm{Np}$ was between those of Optimizations B and $\mathrm{C}$, indicating that reservoir management using control variables can affect oil recovery. Therefore, we concluded that the maximum rates should be included as an additional parameter in optimization to automatically control production rates.

We also noticed a significant increase in $\mathrm{Wp}$ and $\mathrm{Wi}$ in all cases due to changes in fluid movement from the reservoir into wells; a result of boundary condition changes caused by integration, an important issue for production strategy development and reservoir management.

We rechecked the effect of the integration in the production strategy obtained in Optimizations A, B, and C with the same boundary conditions of the base strategy to test for local/global maximum points. Table 8 compares the results of the best strategies for integrated Optimizations $\mathrm{A}, \mathrm{B}$, and $\mathrm{C}$ with and without integration (NPV-I to NPV-ID). The results for optimized integration with production systems showed differences for NPV and Np. Note similar trends in Table 6 (decrease in NPV) although the relative differences were larger in Optimization C. These differences were because production strategy parameters were optimized considering dynamic boundary conditions different to those in the base strategy.

Using cross validation, Table 9 summarizes the NPV-ID value for all cases, which was always lower than the NPV-D for the initial base strategy indicating a global optimum for the standalone simulation. The opposite would indicate that base strategy was at a local optimum.

Based on the NPV (3.06 USD billion), we selected Optimization $\mathrm{B}$ as the best integrated case for implementation. 

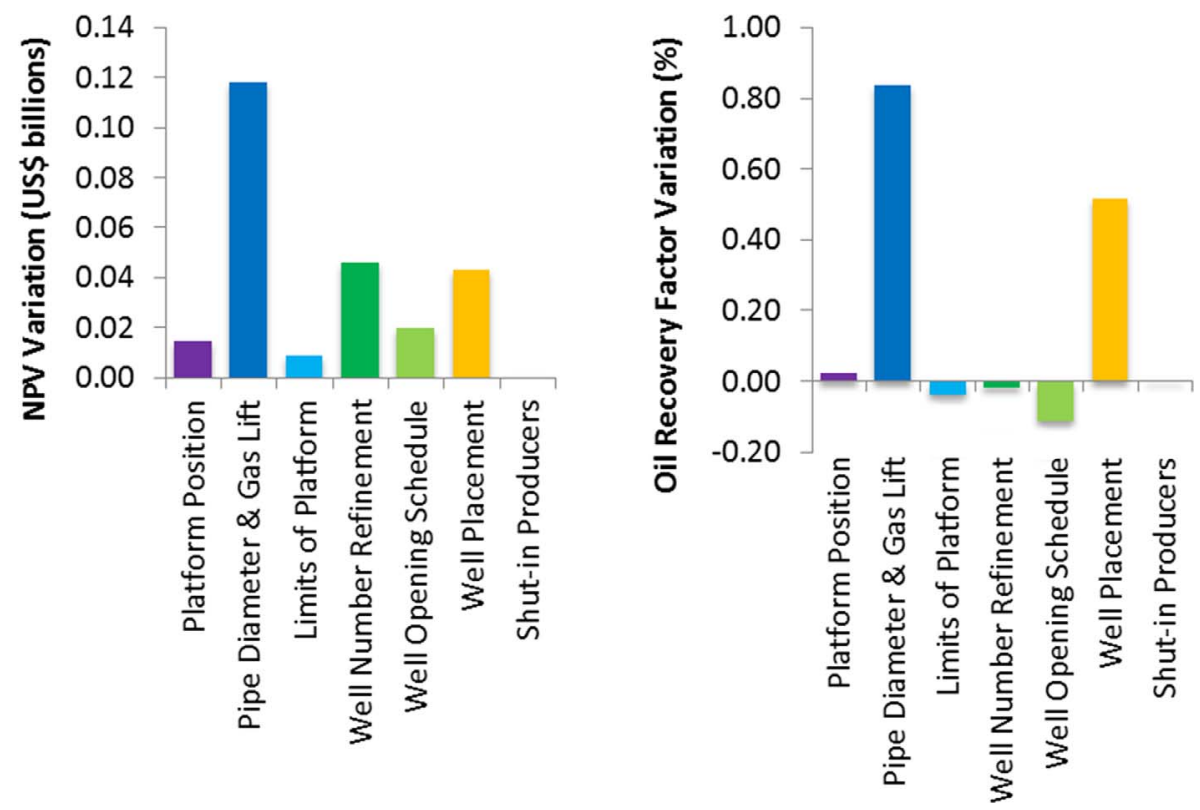

Fig. 7. NPV and Oil Recovery Factor variation for Optimization A.
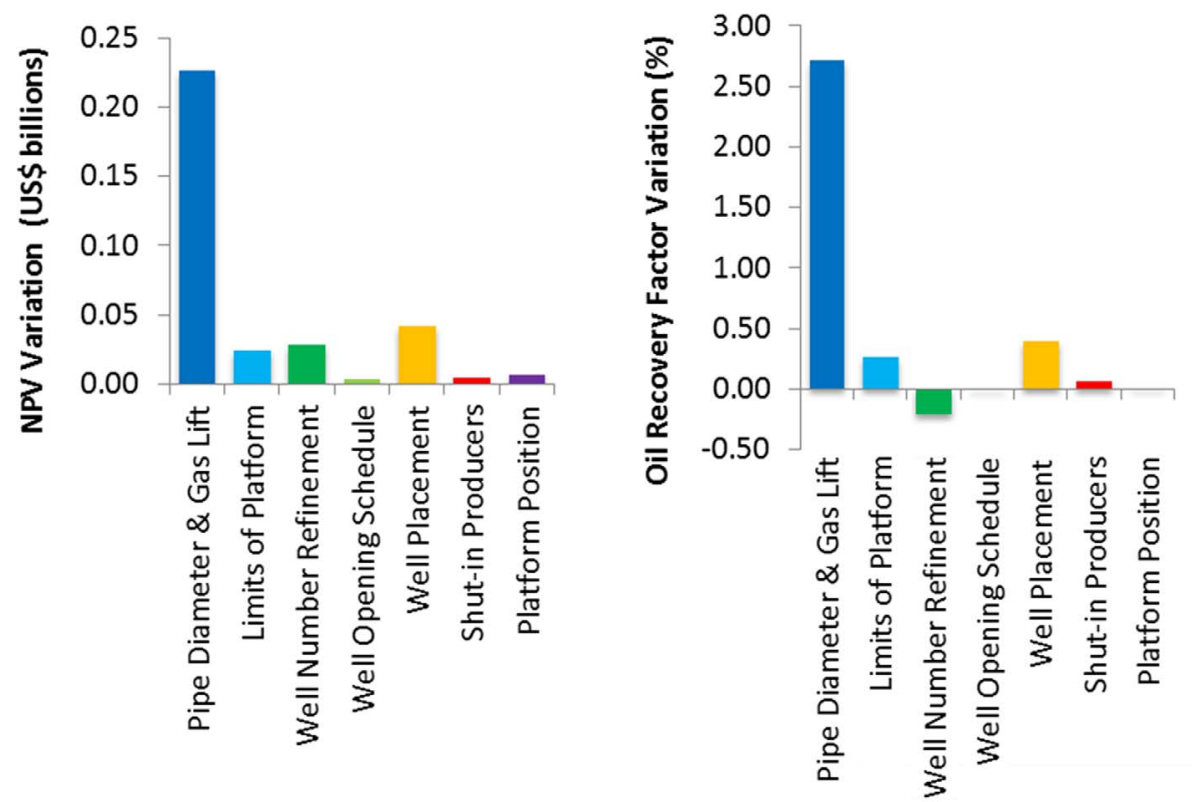

Fig. 8. NPV and Oil Recovery Factor variation for Optimization B.

Variables related to the well and gathering systems of Optimization $\mathrm{B}\left(L_{\mathrm{p}}, d_{r}, d_{\mathrm{pl}}, d_{\mathrm{pc}^{\prime \prime}}\right.$ and $\left.q_{\mathrm{gl}}^{i}\right)$ were set to integrate base strategy in the RM9 representative model, resulting in an NPV of 2.95 USD billion. The best results were for Optimization B strategy, which showed increases for NPV $(3.6 \%), N_{\mathrm{p}}(0.9 \%), W_{\mathrm{p}}(3.9 \%)$, and $W_{\mathrm{i}}(1.7 \%)$ over the base strategy.

\subsection{Implementation step}

To evaluate project risk inside step 11, Figure 13 shows the NPV for the integrated base strategy and Optimization B production strategy for all RMs (RM1 to RM9) and for the reference model after implementation. Optimization B resulted in higher NPVs than the integrated base strategy 

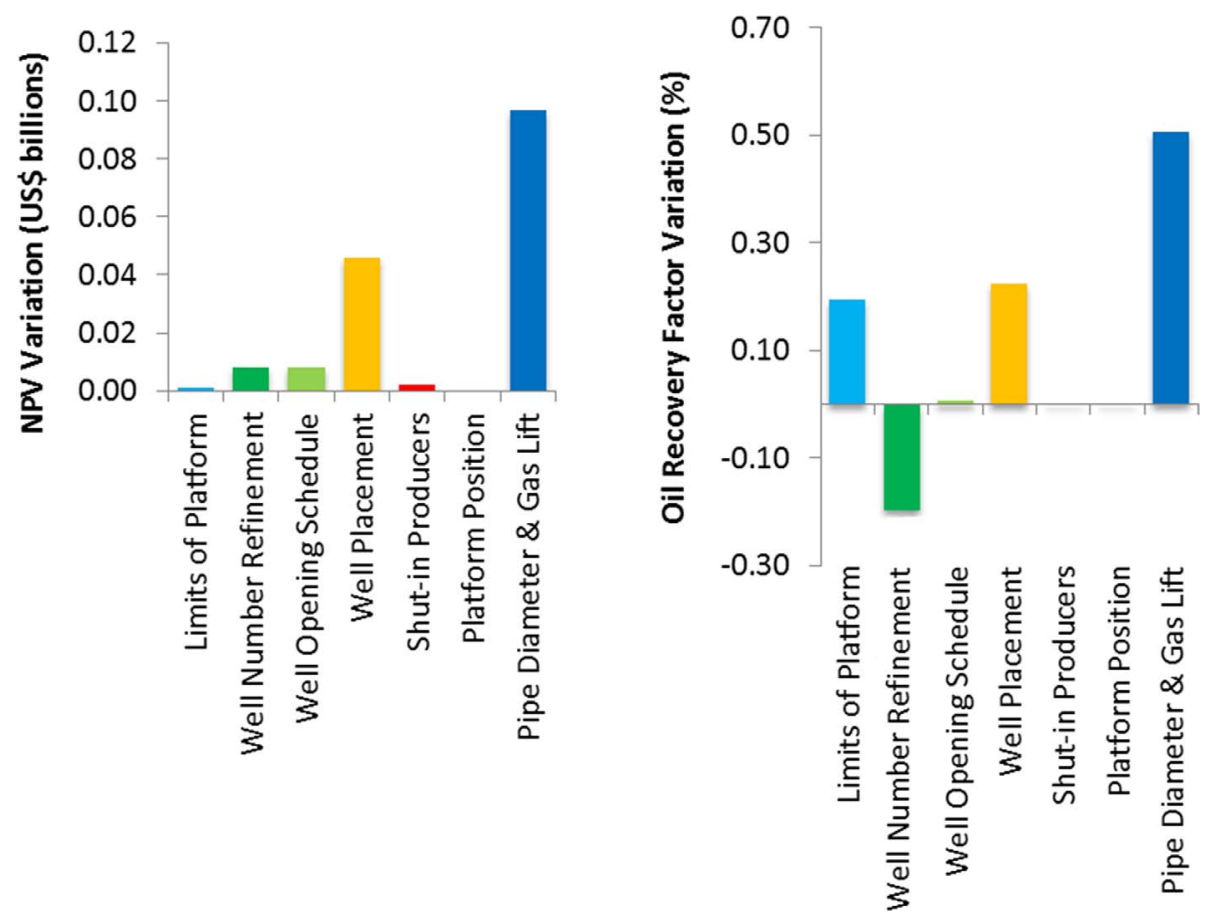

Fig. 9. NPV and Oil Recovery Factor variation for Optimization C.

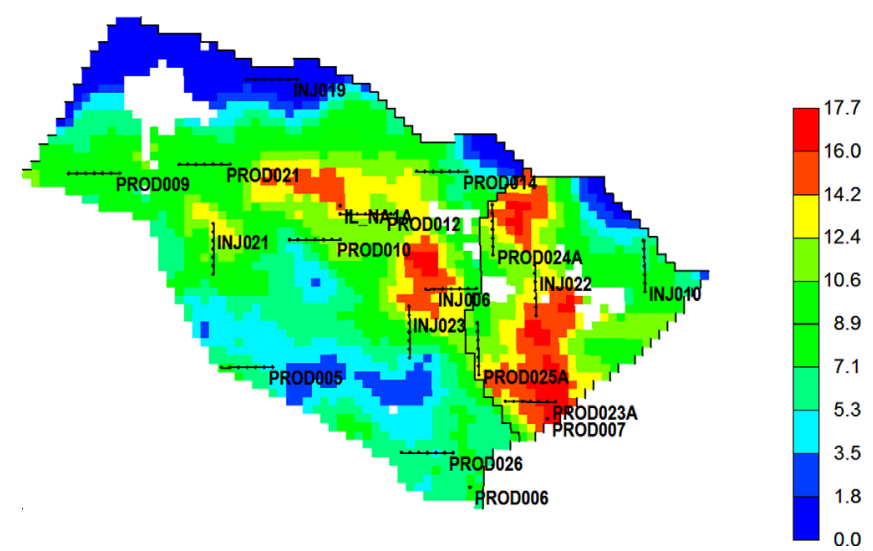

Fig. 10. Well and platform locations after global optimization for Optimization A.

for all RMs, indicating Optimization B as a robust production strategy for implementation in the field.

The implementation of the integrated base strategy in the reference model resulted in a lower NPV (1.47 USD billion) than that obtained in optimization step. The same occurred to Optimization B (1.51 USD billion). It reveals that RM9 did not represent the real field (reference model).

Despite this, the implementation showed increased values for NPV $(6.6 \%), N_{\mathrm{p}}(1.8 \%), W_{\mathrm{p}}(15.3 \%)$, and $W_{\mathrm{i}}(7.3 \%)$ for Optimization B over the integrated base case.

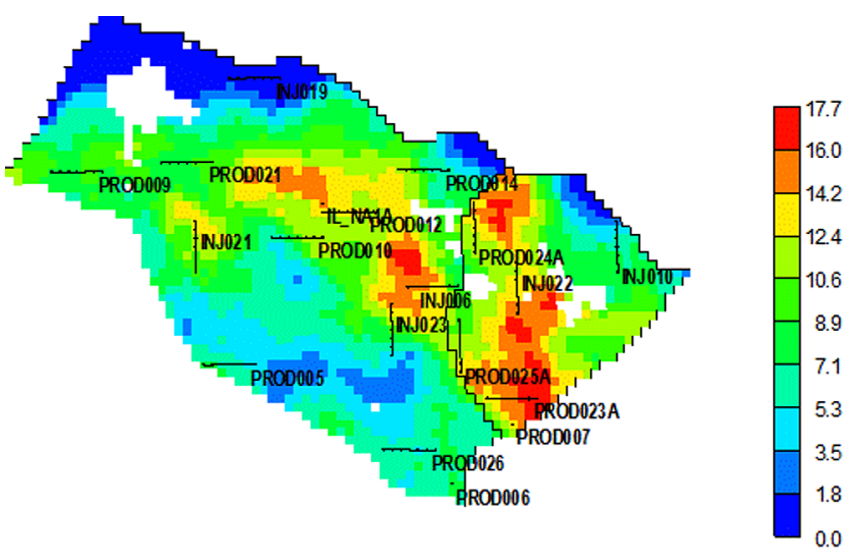

Fig. 11. Well and platform locations after global optimization for Optimization B.

Using the integration in the reference model, we obtained results more compatible with the base strategy, and so, a higher NPV.

The higher percentages of increased NPVs of the integration during implementation than representative model analysis indicated that the production forecast (and consequently economic evaluation) is more sensitive to integration in the implementation step than captured in the optimization step of this study. It also confirmed previous risk analyses, indicating the production strategy of Optimization B to be better than the base strategy (Fig. 13). 

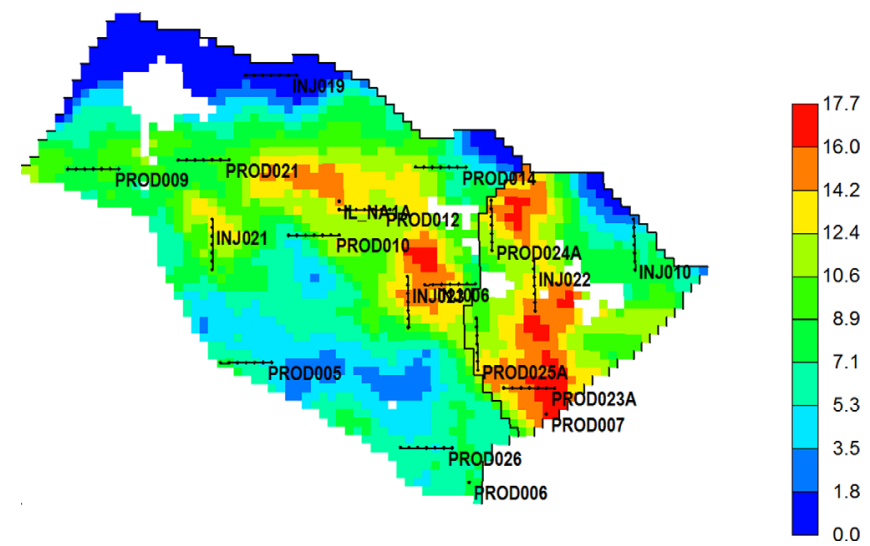

Fig. 12. Well and platform locations after global optimization for Optimization C.

Table 6. Effect of integration on the reservoir performance indicators (using base strategies).

\begin{tabular}{lcccc}
\hline NPV-D to NPV-DI & $\Delta \mathrm{NPV}$ & $\Delta N_{\mathrm{p}}$ & $\Delta W_{\mathrm{p}}$ & $\Delta W_{\mathrm{i}}$ \\
\hline Optimization A & $-2.7 \%$ & $-2.0 \%$ & $8.0 \%$ & $3.8 \%$ \\
Optimization B & $-5.5 \%$ & $-3.7 \%$ & $-41.8 \%$ & $-14.7 \%$ \\
Optimization C & $-0.7 \%$ & $0.2 \%$ & $-0.1 \%$ & $0.0 \%$ \\
\hline
\end{tabular}

Table 7. Effect of integration on the production strategy optimization process.

\begin{tabular}{lcccc}
\hline NPV-DI to NPV-I & $\Delta$ NPV & $\Delta N_{\mathrm{p}}$ & $\Delta W_{\mathrm{p}}$ & $\Delta W_{\mathrm{i}}$ \\
\hline Optimization A & $+8.9 \%$ & $+2.1 \%$ & $+1.5 \%$ & $+0.9 \%$ \\
Optimization B & $+12.2 \%$ & $+5.7 \%$ & $+91.2 \%$ & $+22.4 \%$ \\
Optimization C & $+5.7 \%$ & $+1.3 \%$ & $+11.7 \%$ & $+4.3 \%$ \\
\hline
\end{tabular}

Table 8. Effects of unintegrated boundary conditions on integrated production strategies.

\begin{tabular}{lcccc}
\hline NPV-I to NPV-ID & $\Delta$ NPV & $\Delta N_{\mathrm{p}}$ & $\Delta W_{\mathrm{p}}$ & $\Delta W_{\mathrm{i}}$ \\
\hline Optimization A & $-6.1 \%$ & $-0.7 \%$ & $-10.1 \%$ & $-5.3 \%$ \\
Optimization B & $-7.3 \%$ & $-1.5 \%$ & $-12.7 \%$ & $-4.7 \%$ \\
Optimization C & $-11.5 \%$ & $-3.2 \%$ & $-15.5 \%$ & $-7.0 \%$ \\
\hline
\end{tabular}

We also noticed significant increases for $W_{\mathrm{p}}$ and $W_{\mathrm{i}}$ in implemented cases due to changes in fluid movement from the reservoir into wells; a result of boundary conditions changes caused by integrating reservoir and production systems.

All results show that the 12-step methodology requires a robust integration between reservoir and production systems in step 11 to include modifications in the final strategy, such as well placements, well number, well and
Table 9. Cross validation step, testing strategies for Optimizations A, B and C in an unintegrated process.

\begin{tabular}{lcccc}
\hline NPV-D to NPV-ID & $\Delta$ NPV & $\Delta N_{\mathrm{p}}$ & $\Delta W_{\mathrm{p}}$ & $\Delta W_{\mathrm{i}}$ \\
\hline Optimization A & $-0.4 \%$ & $-0.7 \%$ & $-1.4 \%$ & $3.8 \%$ \\
Optimization B & $-1.7 \%$ & $0.2 \%$ & $-2.8 \%$ & $-14.7 \%$ \\
Optimization C & $-7.1 \%$ & $-1.9 \%$ & $-5.7 \%$ & $0.0 \%$ \\
\hline
\end{tabular}

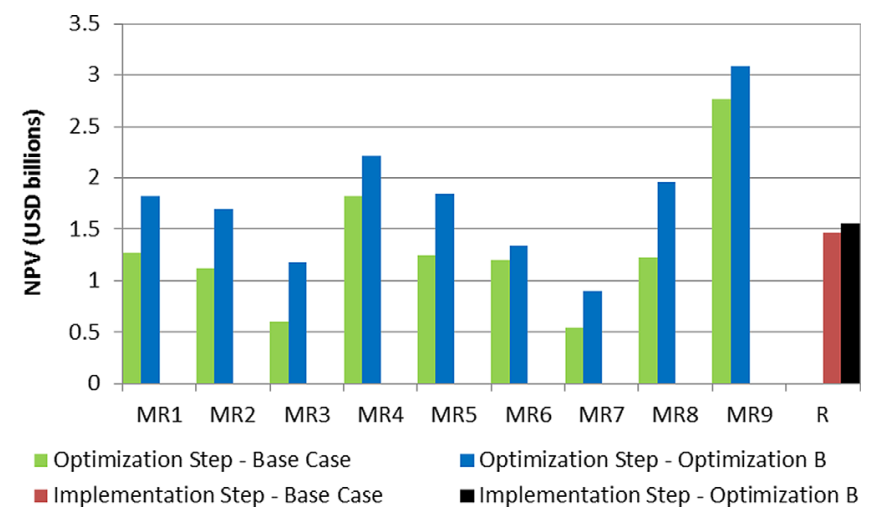

Fig. 13. Risk analysis for integrated base strategy and Optimization B using representative models.

gathering systems characteristics, and platform capacities. As this case was not very complex and because of the recovery process (water flooding), the differences were small enough to include the integration in step 11, separately from steps $6-10$, which focus on optimizing parameters more related to reservoir performance.

\section{Conclusion}

Comparing standalone and integrated production strategies along the optimization process of production strategy for a benchmark case, we noted areas for improvement for well placement, well number, and platform capacity for standalone strategy. These suboptimal areas indicated the necessity of integrating reservoir and production systems into the decision-making process due to dynamic changes in boundary conditions at coupling points, which can positively or negatively affect the chosen objective function.

Results show that well placement remains a fundamental design variable in the optimization process. After systems integration, a few variations in the position of the wells significantly increased the NPV.

The configuration of the well diameters and the application of an artificial method of gas lift also proved to be important design and control variables, with improvements in NPV and RF in our case.

The results showed other variables such as shut-in producer wells and platform capacity to affect NPV less, while well control variables had little impact on NPV but a significant impact on RF, related to reservoir management. 
The integration of production systems and reservoirs resulted in significant changes to the production strategy and NPV of the project, demanding its inclusion in the optimization processes and decision making. The cross-comparison of NPV values indicated that the unintegrated application of the initial case fell short of a global optimum and the integrated optimization obtained higher NPVs.

Testing all representative models (RMs), we noticed that, in this benchmark case, the changes made after the integration were good in all RMs ensuring that the optimized strategy is suitable for application in the reference model.

We noted the respective difference in percentages were greater in results of integration during implementation compared to representative model analysis. When testing in the reference model, we found that, by using the integrated strategy, we had more compatible results with the base strategy. This suggests that integration resulted in more realistic forecasts as well as better NPV than integration in the optimization step.

We demonstrated the advantage of integrating reservoir and production systems to achieve a more robust strategy through optimizing the objective function, and recommend its inclusion in step 11 of the 12-step methodology by integrating and re-optimizing of the production strategy of the standalone production development obtained from early steps. Further tests are necessary to determine the need for integration in earlier steps of the methodology (considering integration at each optimization step of the methodology).

Acknowledgments. This work was conducted with the support of Energi Simulation and Petrobras within the ANP R\&D tax as "commitment to research and development investments". The authors are grateful for the support of the Center of Petroleum Studies (CEPETRO-UNICAMP/Brazil), the Department of Energy (DE-FEM-UNICAMP/Brazil) and Research Group in Reservoir Simulation and Management (UNISIM-UNICAMP) $B r a z i l)$. In addition, special thanks to $C M G$ for software licenses.

\section{References}

Abellan A., Noetinger B. (2010) Optimizing subsurface field data acquisition using information theory, Math. Geosci. 42, 6, 603-630, https://doi.org/10.1007/s11004-010-9285-6.

Avansi G.D., Schiozer D.J. (2015) UNISIM-I: synthetic model for reservoir development and management applications, IJMSPI 9, 1, 21-30.

Barroso Viseras F.J., Blanchais S., Verdiere S., Bouzarkouna Z., Schaeffner A., Jannes P. (2014) Non-deterministic approach to define a robust development plan: a complex mature carbonate field case study, in: Abu Dhabi International Petroleum Exhibition and Conference, https://doi.org/ 10.2118/171904-ms.

Barroux C.C., Duchet-Suchaux P., Samier P., Nabil R. (2000) Linking reservoir and surface simulators: how to improve the coupled solutions, in: SPE European Petroleum Conference, https://doi.org/10.2118/65159-ms.

Bento D.F., Schiozer D.J. (2010) The influence of the production lines pressure drop in the definition of the oilfield drainage strategy, in: SPE Latin American and Caribbean Petroleum Engineering Conference, https://doi.org/10.2118/138259-ms.
Bouzarkouna Z., Ding D.Y., Auger A. (2011) Well placement optimization with the covariance matrix adaptation evolution strategy and meta-models, Comput. Geosci. 16, 1, 75-92, https://doi.org/10.1007/s10596-011-9254-2.

Bouzarkouna Z., Ding D.Y., Auger A. (2013) Partially separated metamodels with evolution strategies for well-placement optimization, SPE J. 18, 06, 1003-1011, https://doi.org/ 10.2118/143292-pa.

Brill J.P., Beggs H.D. (1991) Two-phase flow in pipes, 6th edn. Third Printing, University of Tulsa, Tulsa, Oklahoma,

Campozana F.P., Dos Santos R.L., Madeira M.G., Sousa S.H.G., Spinola M. (2008) Optimization of surface network and platform location using a next generation reservoir simulator coupled with an integrated asset optimizer - an application to an offshore deep water oil field in Brazil, in: International Petroleum Technology Conference, https://doi.org/10.2523/ iptc-12500-ms.

Cotrim H.A., von Hohendorff Filho J.C., Schiozer D.J. (2011) Production optimization considering interaction between reservoirs and constrained surface facilities, in: SPE Reservoir Characterisation and Simulation Conference and Exhibition, https://doi.org/10.2118/148334-ms.

Fonseca L.A., Araújo E.R. (2016) Simultaneous optimization of well locations and control rates under geological uncertainty, IJMSPI 9, 1-7.

Gaspar A.T.F.S., Barreto C.E.A.G., Muñoz Mazo E.O., Schiozer D.J. (2014) Application of Assisted Optimization to Aid Oil Exploitation Strategy Selection for Offshore Fields. SPE Latin America and Caribbean Petroleum Engineering Conference, https://doi.org/10.2118/169464-ms.

Gaspar A.T.F.S., Avansi G.D., Santos A.A.S., Hohendorff Filho J.C.V., Schiozer D.J. (2015) UNISIM-I-D: benchmark studies for oil field development and production strategy selection, IJMSPI 9, 47-55.

Gaspar A.T.F.S., Barreto C.E.A.G., Schiozer D.J. (2016) Assisted process for design optimization of oil exploitation strategy, J. Petrol. Sci. Eng. 146, 473-488, https://doi.org/ 10.1016/j.petrol.2016.05.042.

Guerillot D., Roggero F. (1998) Method for predicting, by means of an inversion technique, the evolution of the production of an underground reservoir, US Patent No. 5,764,515. 9 June.

Hegstad B.K., Saetrom J. (2014) Using multiple realizations from an integrated uncertainty analysis to make more robust decisions in field development, in: Abu Dhabi International Petroleum Exhibition and Conference, https://doi.org/ 10.2118/171831-ms.

Hiebert A.D., Khoshkbarchi M., Sammon P.H., Alves I.N., Rodrigues J., Belien A.J., Valvatne P.H. (2011) An Advanced framework for simulating connected reservoirs, wells and production facilities, in: SPE Reservoir Simulation Symposium, https://doi.org/10.2118/141012-ms.

Kosmala A., Aanonsen S.I., Gajraj A., Biran V., Brusdal K., Stokkenes A., Torrens R. (2003) Coupling of a surface network with reservoir simulation, in: SPE Annual Technical Conference and Exhibition, https://doi.org/10.2118/84220-ms.

Magalhães, T.C.B., Martini, R.F., Schiozer, D.J. (2005). The influence of production system constraints on the reservoir strategy optimization, in: $18^{\circ}$ Congresso Internacional de Engenharia Mecânica-COBEM.

Mahmudi M., Sadeghi M.T. (2013) The optimization of continuous gas lift process using an integrated compositional model, J. Petrol. Sci. Eng. 108, 321-327, https://doi.org/10.1016/ j.petrol.2013.05.008. 
Maschio C., Vidal A.C., Schiozer D.J. (2008) A framework to integrate history matching and geostatistical modeling using genetic algorithm and direct search methods, J. Petrol. Sci. Eng. 63, 1-4, 34-42, https://doi.org/10.1016/j.petrol.2008. 08.001.

Nwakile M.M., Schulze-Riegert R., Trick M.D. (2011) Gas field production system optimization using coupled reservoir network simulator and optimization framework, in: Nigeria Annual International Conference and Exhibition, https://doi.org/10.2118/150770-ms.

Oliveira L.C.G. (1989) Simulador para Rede Coletora Submarina de Produção, Master's Thesis, Faculdade de Engenharia, Departamento de Engenharia Mecânica, Universidade Estadual de Campinas, Campinas, 248 p.

Rahmawati S.D., Whitson C.H., Foss B., Kuntadi A. (2012) Integrated field operation and optimization, J. Petrol. Sci. Eng. 81, 161-170, https://doi.org/10.1016/j.petrol.2011. 12.027.

Ray T., Sarker R. (2007) Genetic algorithm for solving a gas lift optimization problem, J. Petrol. Sci. Eng. 59, 1-2, 84-96, https://doi.org/10.1016/j.petrol.2007.03.004.

Rosa V.R., Martins Ferreira Filho V. J. (2012) Optimizing the location of platforms and manifolds, in: Volume 6: Materials Technology; Polar and Arctic Sciences and Technology; Petroleum Technology Symposium, https://doi.org/10.1115/ omae2012-84211.

Rotondi M., Cominelli A., Di Giorgio C., Rossi R., Vignati E., Carati B. (2008) The Benefits of integrated asset modelling: lessons learned from field cases, in: Europec/EAGE Conference and Exhibition, https://doi.org/10.2118/113831-ms.
Schiozer D.J., Santos A.A.S., Drumond P.S. (2015) Integrated model based decision analysis in twelve steps applied to petroleum fields development and management, in: EUROPEC 2015, https://doi.org/10.2118/174370-ms.

Standing M.B. (1947) A pressure-volume-temperature correlation for mixtures of California oils and gases, API, Drill Prod Pract, pp. 275-287.

Tillero E., Rincón J., Nuñez H. (2014) An Innovative workflow for appropriate selection of subsurface-surface model integration scheme based on petroleum production system nature, user needs, and integrated simulation performance, in: SPE Latin America and Caribbean Petroleum Engineering Conference, https://doi.org/10.2118/169243-ms.

Victorino I.R.S., Hohendorff Filho J.C.V., Schiozer D.J. (2016) Sensibility analysis of production system parameters for integrated simulation of reservoir and production systems, in: Rio Oil Gas Expo and Conference.

Von Hohendorff Filho J.C., Schiozer D.J. (2014) Evaluation of explicit coupling between reservoir simulators and production system, J. Energy Resour. Technol. 136, 4, 044501, https://doi.org/10.1115/1.4028860.

Von Hohendorff Filho J.C., Schiozer D.J. (2017) Evaluation of reservoir and production system integration in production strategy selection, in: SPE Reservoir Simulation Conference, https://doi.org/10.2118/182624-ms.

Yang C., Nghiem L.X., Card C., Bremeier M. (2007) Reservoir model uncertainty quantification through computer-assisted history matching, in: SPE Annual Technical Conference and Exhibition, https://doi.org/10.2118/109825-ms. 